\title{
Comparison of cone-beam computed tomography and panoramic radiography for mandibular morphometry
}

\author{
M. Tassoker ${ }^{1}$, D. Akin², A.D. Aydin Kabakci², S. Sener ${ }^{1}$ \\ ${ }^{1}$ Department of Oral and Maxillofacial Radiology, Faculty of Dentistry, Necmettin Erbakan University, Konya, Turkey \\ 2Department of Anatomy, Meram Medicine Faculty, Necmettin Erbakan University, Konya, Turkey
}

[Received: 1 November 2018; Accepted: 15 February 2019]

Background: The aim of this study was to compare the morphological differences in the mandible between patients with six age groups and to detect the correlation between these parameters on panoramic radiography (PR) and cone-beam computed tomography (CBCT).

Materials and methods: A total of 121 subjects (50 males and 71 females) were included in the study and were divided into six age groups (10-19, 20-29, 30-39, 40-49, 50-59, and 60-69) on the basis of the chronological age. CBCT and $P R$ methods were used to record the mandibular measurements for the same 121 patients. Differences between male and female mandibular morphometric measurements, between right and left side measurements, and differences in age subgroups compared by using independent samples t-test, paired samples t-test, and one-way ANOVA test, respectively. $P<0.05$ value was considered statistically significant for all analysis.

Results: Males mostly have higher mandibular measurement values. There were statistically significant differences between CBCT and PR measurements $(p<0.05)$. $P R$ mostly showed higher values than CBCT measurements.

Conclusions: Based on the fact that PRs showing significant differences from $C B C T$ in the morphometric measurements made on mandible, it is recommended that forensic doctors and anthropologists consider this information in their age and gender prediction studies. (Folia Morphol 2019; 78, 4: 862-870)

Key words: gonial angle, mandible, panoramic radiography, cone-beam computed tomography, morphology

\section{INTRODUCTION}

Morphological characteristics of the mandible show differences in age, sex, dental status, and race [8]. Various skeletal morphological features can be used for sex determination. Visual analysis of the human skeleton is challenging, thus the assessment of bones requires the use of metric analysis, which provides objectiveness [30]. The mandible is the most reliable gender indicator in the craniofacial skeleton [30].
The gonial angle (GA), one of the mandibular morphometric measurements, is formed by the intersection of a tangent to the posterior border of the ramus and a tangent to the lower border of the mandible $[2,4]$. The GA can be measured on lateral cephalograms but reliable measurement becomes difficult because of superimpositions [35]. Panoramic radiography (PR) was introduced by Paatero in 1961 [4], and since then it has been used as one of the

Address for correspondence: Dr. M. Tassoker, Necmettin Erbakan University, Faculty of Dentistry, Department of Oral and Maxillofacial Radiology, Ankara cd, 42050, Konya, Turkey, fax: 0903322200025, e-mail: dishekmelek@gmail.com 
essential imaging tools in dentistry. PR can be used for reliable bilateral measurement of the GA without superimpositions [4]. Computed tomography (CT) [18] and cone-beam CT (CBCT) [11] can also be used for $\mathrm{GA}$ measurement. CBCT is a recently introduced, three-dimensional (3D) imaging technique requiring a lower effective radiation dose than CT [32]. Early studies have revealed that CBCT measurements of the human dry skull are highly accurate and reproducible [17].

The GA has clinical importance in diagnosing craniofacial disorders. It is an important angle of the craniofacial complex, giving an indication about the symmetry of the facial skeleton [4]. Based on the $\mathrm{GA}$, individuals can be categorised as having a high, normal, or low angle or vertical, normal, or horizontal growth [25]. On the other hand, it has been suggested that a high GA constitutes a risk of mandibular angle fracture [25].

At birth, the masticatory muscles and mandibular bone are on average $4-12 \%$ larger in males than in females [7], and masticatory forces, which influence the shape and size of the mandibular ramus, also differ between genders [1]. The shape of the GA correlates with the function of the jaw-closing masticatory muscles [35]. in dentate individuals, strong masseter and anterior temporal muscles lead to a small GA. Due to the chronic and progressive resorption of the residual ridge after tooth extraction, the GA is larger in the edentulous stage [35]. The morphology of the masseter muscles also differs between dentate and edentulous people, being larger in dentate individuals [35]. Moreover, advancing age influences mandibular morphology: With the remodelling process $[2,6,14]$, masticatory muscles change in function and show lower muscle density [31].

Sex identification in bone remnants is important in forensic practice and forensic anthropology. The skull is the most dimorphic portion of skeleton, providing, after the pelvis, an accuracy of up to $92 \%[1,8]$. The GA can be used as a tool in forensic odontology [31]. Most studies have investigated the GA only for age and sex determination, but it is suggested that the GA alone is not sufficient to determine age and sex due to the presence of multiple factors influencing mandibular morphology [19]. This retrospective study was performed to assess mandibular morphometry with various parameters and evaluate any variation between gender and age by using CBCT scans and digital PR.

\section{MATERIALS AND METHODS}

\section{Sample and study design}

The study consisted of archived panoramic and CBCT images of 121 patients (50 males and $71 \mathrm{fe}-$ males) aged between 10 and 69 years, referred to our Radiology Department between 2014 and 2017 for diagnosis and treatment of impacted teeth, implant surgery, orthodontic evaluation, and so on. After $\mathrm{CBCT}$, these patients were subjected to PR examination. The study protocol was approved by the Ethics Committee in Research of the Faculty of Dentistry, Necmettin Erbakan University, Konya, Turkey (No. 2017/04).

The patients were divided into six chronological age groups $(10-19,20-29,30-39,40-49,50-59$, and 60-69). The 10-29-year-old group was considered relatively young, 30-49 was in the middle, and 50-69 years was the older age group. Demographic data of the subjects are summarised in Table 1. Exclusion criteria were the presence any of maxillofacial fracture, history of maxillofacial surgery, developmental anomaly, temporomandibular joint dysfunction, mandibular pathology, metabolic disease, and endocrine disturbances affecting the craniofacial region. Edentulous individuals were also excluded from the study. The 242 hemimandibles were evaluated on both digital PRs and CBCT images by the same observer who had had at least 5 years' oral and maxillofacial radiology experience.

Reformatted panoramic reconstructions of CBCTs were used for the study. To ensure standardisation of the $\mathrm{CBCT}$ measurements, the software was oriented parallel to the occlusal surface. The panoramic tool of the software was used as the reference axial slice to reconstruct the $\mathrm{CBCT}$ data. Markings were made on the axial CBCT images as proposed by Ludlow et al. [20] for panoramic reconstruction to ensure that the landmarks to be used for measurement were in the view of the reformatted panoramic CBCT slice (Fig. 1). CBCT images were generated with a 3D Accuitomo 170 device (J Morita Mfg Co), adjusted at $90 \mathrm{kVp}$, $5 \mathrm{~mA}, 17.5 \mathrm{~s}$, irradiation time, $0.25-\mathrm{mm}$ voxel size, and a $17 \times 14-\mathrm{cm}$ field of view. Patients were placed in a horizontal position, stabilised with custom-made head bands and chin supports, and monitored to ensure that they remained motionless throughout the scanning.

The reliability of the PR method is highly dependent on patient head position [19]. To avoid distortions and eliminate patient positioning errors, the 
Table 1. The demographic profile of the sample

\begin{tabular}{lccccc}
\hline Gender & N $(\%)$ & \multicolumn{3}{c}{ Age } & P \\
\cline { 3 - 5 } & & Minimum & Maximum & Mean \pm SD & \\
\hline Male & $50(41.3 \%)$ & 10 & 67 & $25.64 \pm 15.50$ & $0.154^{*}$ \\
Female & $71(58.7 \%)$ & 13 & 69 & $29.89 \pm 16.77$ & \\
Total & $121(100 \%)$ & 10 & 69 & $28.13 \pm 16.33$ & \\
\hline
\end{tabular}

${ }^{*}$ Statistically significant difference was assumed at $\mathrm{p}<0.05 ; \mathrm{N}-$ total number of cases; Mean $\pm \mathrm{SD}$ - mean value \pm standard deviation; $\mathrm{p}-$ significance level

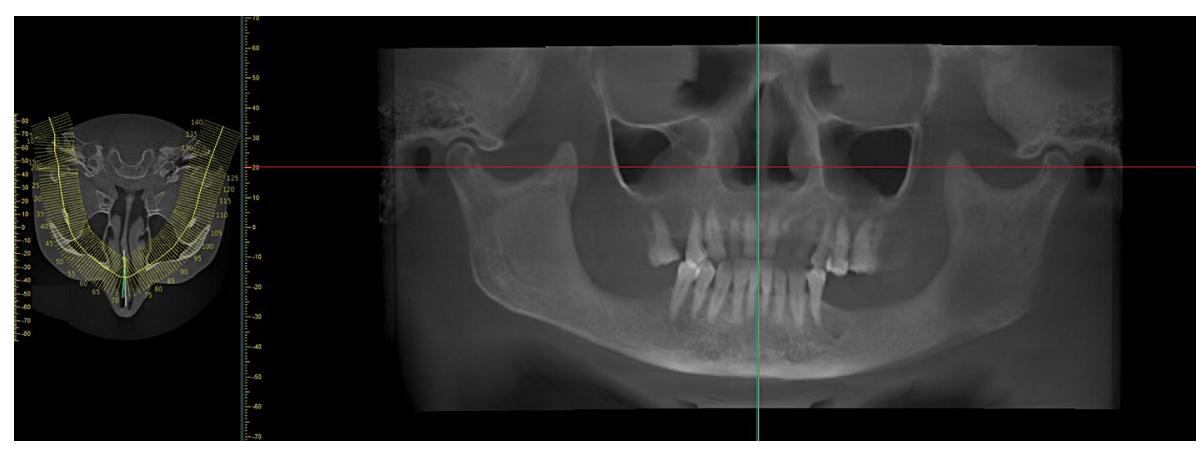

Figure 1. The acquisition of reformatted panoramic cone-beam computed tomography (CBCT) image from axial CBCT slice.

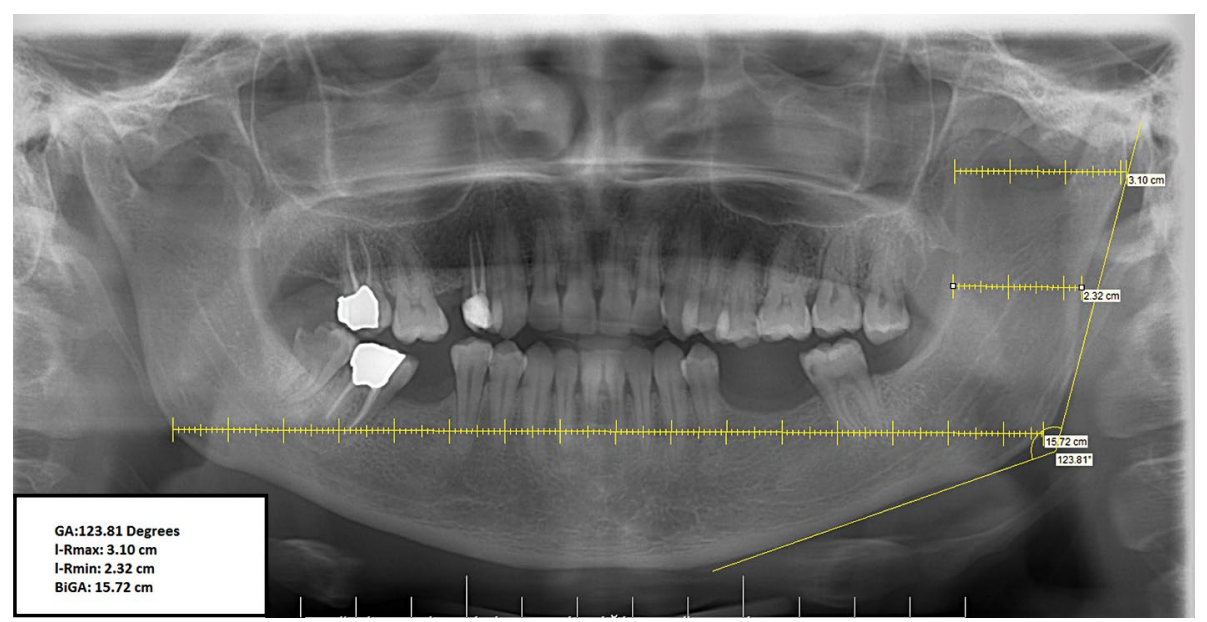

Figure 2. The measurements were made by panoramic radiography; GA — gonial angle; Rmax — maximum ramus breadth; Rmin — minimum ramus breadth; BiGA — bigonial width.

Frankfurt horizontal plane was adjusted parallel to the floor and the heads of all patients were stabilised. Additionally, all PRs were taken by same technician with the same PR device (2D Veraviewpocs, J Morita, MFG Co, Kyoto, Japan), using standard exposure parameters (65-kV tube voltage, 5-mA tube current, and 14.8-s exposure time). All CBCT reconstructions and measurements on PR and CBCT images were accomplished with the use of the i-Dixel software Ver. 2.0 (J Morita MFG Co.).

\section{Measurement procedure}

Two anthropometric landmarks were marked out and five measurements were described as follows:

- gonion (Go) - most inferior, posterior, and lateral point on the angle of the mandible;

- condylion (Co) - most superior and posterior point of the mandibular condyle;

- gonial angle (GA) - angle between lower border of the mandibular body and the posterior borders of the ramus and condyle; 


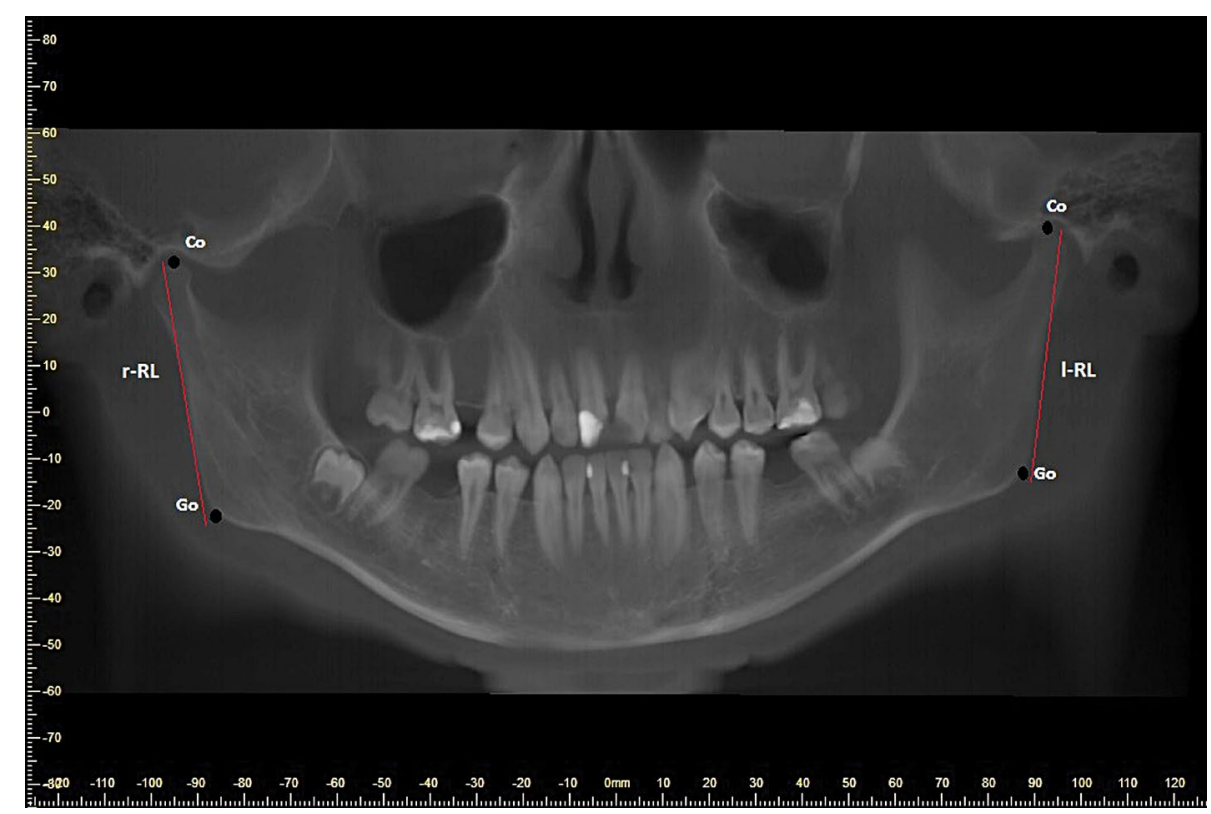

Figure 3. The measurements were made by cone-beam computed tomography; $r$ - right; I — left; $\mathrm{RL}$ — ramus length; Co — condylion; Go-gonion.

- ramus length ( $\mathrm{RL})$ - distance between condylion and gonion;

- maximum ramus breadth (Rmax) - largest anteroposterior diameter of the ramus;

- minimum ramus breadth (Rmin) - smallest anteroposterior diameter of the ramus;

- bigonial width (BiGA) - distance between the two gonions.

Measurements made by digital PRs and CBCTs are given in Figures 2 and 3.

\section{Statistical analysis}

Data obtained from the study were assessed using SPSS software (ver. 21; SPSS, Inc.). To test intra-examiner reliability, measurements were repeated with 25 randomly selected patients, and intraclass correlation coefficient (ICC) values were calculated. Descriptive statistics for all variables were calculated. Quantitative variables were checked as if they fit in normal distribution by using the Shapiro-Wilk test. Differences between male and female mandibular morphometric measurements, between right- and left-side measurements, and differences in age subgroups were compared by using the independent-samples $t$ test, paired samples $t$ test, and one-way ANOVA, respectively. $P<0.05$ was considered statistically significant for all analyses.

\section{RESULTS}

The ICC values for PR (0.82-0.87) and CBCT (0.89$-0.95)$ showed good intra-examiner agreement. The overall mean age of the sample was $28.13 \pm 16.33$ years and, although the average age for females was slightly higher, the difference was not statistically significant ( $p>0.05, p=0.154$; Table 1$)$.

The CBCT and PR measurements are demonstrated in Table 2 . There were statistically significant differences between CBCT and PR measurements $(p<0.05)$. PR showed higher values than did CBCT $(p=0.000)$ except right-GA measurements, which had almost equal values in PR $\left(118.75 \pm 7.12^{\circ}\right)$ and CBCT $(118.83 \pm$ $\left.\pm 6.76^{\circ}, p=0.867\right)$.

The Student $t$ test was applied to compare the means of the different mandibular measurements between males and females (Table 3). Males have mostly higher mandibular measurements on PR and CBCT except the GA. According to the PR measurements, right GA and left GA values are almost equal in males and females ( $p>0.05$ ). According to CBCT examinations, right GA and left GA values are higher in females (Table 3).

Tables 4 and 5 demonstrate the means of all measurements in the six different age groups. There was no statistically significant difference between the six age groups in PR measurements. For CBCT measurements, only Rmax values showed statistically significant differ- 
Table 2. Minimum, maximum, mean and standard deviation values of the data obtained from all cases

\begin{tabular}{|c|c|c|c|c|c|c|c|}
\hline \multirow[t]{2}{*}{ Parameter } & \multicolumn{3}{|c|}{ Panoramic radiography $(\mathrm{n}=121)$} & \multicolumn{3}{|c|}{ Cone-beam computed tomography $(\mathrm{n}=121)$} & \multirow[t]{2}{*}{$\mathbf{P}$} \\
\hline & Min & Max & Mean \pm SD & Min & Max & Mean \pm SD & \\
\hline $\mathrm{R} ; \mathrm{GA}$ & 103.80 & 141.70 & $118.75 \pm 7.12$ & 91.82 & 138.53 & $118.83 \pm 6.76$ & 0.867 \\
\hline $\mathrm{R} ; \mathrm{RL}$ & 5.57 & 10.30 & $7.64 \pm 0.87$ & 4.50 & 7.88 & $6.16 \pm 0.66$ & $0.000^{*}$ \\
\hline $\mathrm{R} ; \mathrm{Rmax}$ & 3.50 & 6.13 & $4.56 \pm 0.48$ & 3.01 & 4.85 & $3.95 \pm 0.36$ & $0.000^{*}$ \\
\hline $\mathrm{R} ; \mathrm{Rmin}$ & 2.40 & 4.39 & $3.20 \pm 0.37$ & 2.20 & 3.90 & $2.78 \pm 0.30$ & $0.000^{*}$ \\
\hline BiGA & 16.32 & 24.07 & $20.42 \pm 1.36$ & 14.01 & 20.11 & $16.81 \pm 1.04$ & $0.000^{*}$ \\
\hline $\mathrm{L} ; \mathrm{GA}$ & 99.79 & 137.20 & $120.75 \pm 6.86$ & 102.47 & 133.93 & $118.84 \pm 6.76$ & $0.000^{*}$ \\
\hline $\mathrm{L} ; \mathrm{RL}$ & 4.93 & 10.46 & $7.56 \pm 0.83$ & 4.22 & 8.04 & $6.05 \pm 0.64$ & $0.000^{*}$ \\
\hline L; Rmax & 3.02 & 5.57 & $4.44 \pm 0.42$ & 3.01 & 4.96 & $3.95 \pm 0.38$ & $0.000^{*}$ \\
\hline L; Rmin & 2.30 & 4.18 & $3.13 \pm 0.34$ & 2.18 & 3.78 & $2.74 \pm 0.31$ & $0.000^{*}$ \\
\hline
\end{tabular}

${ }^{*}$ The significance level is $p<0.001 ; n-$ total number of cases; mean $\pm S D$ - mean value \pm standard deviation; $p$ - significance level; $R$ - right; $L-$ left; $G A-$ gonial angle; $\mathrm{RL}$ — ramus length; Rmax — maximum ramus breadth; Rmin — minimum ramus breadth; BiGA — bigonial width

Table 3. Mean values and significance level of all parameters in males and females

\begin{tabular}{|c|c|c|c|c|c|c|}
\hline \multirow[t]{2}{*}{ Parameter } & \multicolumn{3}{|c|}{ Panoramic radiography } & \multicolumn{3}{|c|}{ Cone-beam computed tomography } \\
\hline & $\begin{array}{c}\text { Male }(n=50) \\
\text { Mean } \pm \text { SD }\end{array}$ & $\begin{array}{c}\text { Female }(n=71) \\
\text { Mean } \pm \text { SD }\end{array}$ & $\mathbf{P}$ & $\begin{array}{c}\text { Male }(n=50) \\
\text { Mean } \pm \text { SD }\end{array}$ & $\begin{array}{c}\text { Female }(n=71) \\
\text { Mean } \pm \text { SD }\end{array}$ & $\mathbf{P}$ \\
\hline $\mathrm{R} ; \mathrm{GA}$ & $119.23 \pm 7.82$ & $118.40 \pm 6.61$ & 0.541 & $117.13 \pm 7.38$ & $120.03 \pm 6.06$ & $0.024^{*}$ \\
\hline $\mathrm{R} ; \mathrm{RL}$ & $8.06 \pm 0.99$ & $7.34 \pm 0.63$ & $0.000^{* *}$ & $6.51 \pm 0.74$ & $5.92 \pm 0.47$ & $0.000^{* *}$ \\
\hline $\mathrm{R} ; \mathrm{Rmax}$ & $4.78 \pm 0.43$ & $4.42 \pm 0.46$ & $0.000^{* *}$ & $4.11 \pm 0.32$ & $3.84 \pm 0.34$ & $0.000^{* *}$ \\
\hline $\mathrm{R} ; \mathrm{Rmin}$ & $3.29 \pm 0.39$ & $3.14 \pm 0.36$ & 0.039 & $2.89 \pm 0.31$ & $2.70 \pm 0.26$ & $0.001^{*}$ \\
\hline BiGA & $20.96 \pm 1.35$ & $20.03 \pm 1.24$ & $0.000^{* *}$ & $17.42 \pm 0.98$ & $16.38 \pm 0.86$ & $0.000^{* *}$ \\
\hline $\mathrm{L} ; \mathrm{GA}$ & $120.92 \pm 7.99$ & $120.62 \pm 6.00$ & 0.824 & $118.02 \pm 7.88$ & $119.41 \pm 5.84$ & 0.291 \\
\hline $\mathrm{L} ; \mathrm{RL}$ & $7.94 \pm 0.90$ & $7.29 \pm 0.66$ & $0.000^{* *}$ & $6.35 \pm 0.70$ & $5.83 \pm 0.50$ & $0.000^{* *}$ \\
\hline L; Rmax & $4.57 \pm 0.37$ & $4.35 \pm 0.43$ & $0.004^{*}$ & $4.08 \pm 0.38$ & $3.85 \pm 0.35$ & $0.001^{*}$ \\
\hline $\mathrm{L} ; \mathrm{Rmin}$ & $3.14 \pm 0.35$ & $3.13 \pm 0.33$ & 0.836 & $2.87 \pm 0.34$ & $2.65 \pm 0.26$ & $0.000^{* *}$ \\
\hline
\end{tabular}

*The significance level is $p<0.05$; ${ }^{* *}$ The significance level is $p<0.001 ; n-$ total number of cases; mean $\pm S D$ - mean value \pm standard deviation; $p-$ significance level; $R-$ right; $\mathrm{L}$ — left; $\mathrm{GA}$ — gonial angle; $\mathrm{RL}$ — ramus length; Rmax — maximum ramus breadth; Rmin — minimum ramus breadth; BiGA — bigonial width

ences on the right $(p=0.006)$ vs. left side $(p=0.035)$. The lowest values for Rmax were measured in the 10-19 age group; the highest in 40-49 and 60-69 (Tables 4 and 5).

\section{DISCUSSION}

This study was carried out to assess mandibular morphometry using various parameters (GA, RL, Rmax, Rmin, and BiGA) and evaluate any variation in age or gender by using digital PRs and CBCT scans. Those morphometric measurements were preferred because they were the most often used and were found to be the best points in age- and sex-prediction studies [26]. To the best of our knowledge, this is the first study comparing PR and CBCT in evaluating mandibular morphology. Dry-skull PRs are commonly used in forensic investigations and anthropology to predict age and sex of an individual based on the gonial region, condyle, and ramus, which are the various remodelling fields in the mandible [12]. Our results indicated that there were statistically significant differences between CBCT and PR measurements $(p<0.05)$. PR showed higher values than CBCT measurements except those of the right $G A$, which had almost equal values in PR and CBCT. PR is an easily accessible, cheap, and dose-sparing imaging method that has become the first-line tool for examining the teeth and jaws. However, the horizontal and vertical magnification factors of PR inherent in the panoramic technique and variations in patient positioning 
Table 4. Right mean values and significance level of all parameters in panoramic radiography (PR) and cone-beam computed tomography (CBCT) according to age

\begin{tabular}{|c|c|c|c|c|c|c|}
\hline & \multirow[t]{2}{*}{ Age group } & \multirow[t]{2}{*}{$\mathbf{N}$} & \multicolumn{2}{|c|}{ PR } & \multicolumn{2}{|c|}{ СВСТ } \\
\hline & & & Mean \pm SD & $\mathbf{P}$ & Mean \pm SD & $\mathbf{P}$ \\
\hline \multirow[t]{6}{*}{$\mathrm{R} ; \mathrm{GA}$} & $10-19$ & 71 & $120.26 \pm 7.03$ & 0.056 & $119.42 \pm 6.27$ & 0.350 \\
\hline & $20-29$ & 10 & $118.77 \pm 6.46$ & & $118.49 \pm 5.05$ & \\
\hline & $30-39$ & 8 & $116.81 \pm 11.14$ & & $114.2 \pm 13.95$ & \\
\hline & $40-49$ & 14 & $114.73 \pm 5.43$ & & $117.33 \pm 5.01$ & \\
\hline & $50-59$ & 9 & $115.1 \pm 5.59$ & & $119.43 \pm 6.25$ & \\
\hline & $60-69$ & 9 & $118.46 \pm 5.12$ & & $120.47 \pm 5.7$ & \\
\hline \multirow[t]{6}{*}{$\mathrm{R} ; \mathrm{RL}$} & $10-19$ & 71 & $7.52 \pm 0.79$ & 0.149 & $6.07 \pm 0.59$ & 0.186 \\
\hline & $20-29$ & 10 & $7.89 \pm 1.24$ & & $6.47 \pm 0.88$ & \\
\hline & $30-39$ & 8 & $7.51 \pm 1.14$ & & $6.03 \pm 0.82$ & \\
\hline & $40-49$ & 14 & $8.2 \pm 0.98$ & & $6.51 \pm 0.78$ & \\
\hline & $50-59$ & 9 & $7.66 \pm 0.37$ & & $6.18 \pm 0.44$ & \\
\hline & $60-69$ & 9 & $7.58 \pm 0.84$ & & $6.17 \pm 0.72$ & \\
\hline \multirow[t]{6}{*}{$\mathrm{R} ; \mathrm{Rmax}$} & $10-19$ & 71 & $4.48 \pm 0.47$ & 0.082 & $3.86 \pm 0.35$ & $0.006^{*}$ \\
\hline & $20-29$ & 10 & $4.68 \pm 0.44$ & & $4.00 \pm 0.26$ & \\
\hline & $30-39$ & 8 & $4.53 \pm 0.69$ & & $3.96 \pm 0.40$ & \\
\hline & $40-49$ & 14 & $4.85 \pm 0.46$ & & $4.18 \pm 0.41$ & \\
\hline & $50-59$ & 9 & $4.52 \pm 0.33$ & & $4.00 \pm 0.29$ & \\
\hline & $60-69$ & 9 & $4.78 \pm 0.47$ & & $4.24 \pm 0.33$ & \\
\hline \multirow[t]{6}{*}{$\mathrm{R} ; \mathrm{Rmin}$} & $10-19$ & 71 & $3.19 \pm 0.33$ & 0.147 & $2.76 \pm 0.29$ & 0.668 \\
\hline & $20-29$ & 10 & $3.17 \pm 0.57$ & & $2.83 \pm 0.38$ & \\
\hline & $30-39$ & 8 & $3.3 \pm 0.53$ & & $2.87 \pm 0.37$ & \\
\hline & $40-49$ & 14 & $3.41 \pm 0.29$ & & $2.86 \pm 0.24$ & \\
\hline & $50-59$ & 9 & $2.97 \pm 0.33$ & & $2.67 \pm 0.23$ & \\
\hline & $60-69$ & 9 & $3.22 \pm 0.47$ & & $2.78 \pm 0.37$ & \\
\hline \multirow[t]{6}{*}{ BiGA } & $10-19$ & 71 & $20.36 \pm 1.32$ & 0.925 & $16.78 \pm 1.03$ & 0.731 \\
\hline & $20-29$ & 10 & $20.4 \pm 1.74$ & & $16.87 \pm 1.27$ & \\
\hline & $30-39$ & 8 & $20.24 \pm 1.14$ & & $16.89 \pm 1.33$ & \\
\hline & $40-49$ & 14 & $20.81 \pm 1.3$ & & $17.19 \pm 0.97$ & \\
\hline & $50-59$ & 9 & $20.49 \pm 1.11$ & & $16.49 \pm 0.67$ & \\
\hline & $60-69$ & 9 & $20.43 \pm 1.98$ & & $16.72 \pm 1.21$ & \\
\hline
\end{tabular}

*The significance level is $\mathrm{p}<0.05 ; \mathrm{n}$ - total number of cases; Mean $\pm \mathrm{SD}$ - mean value \pm standard deviation; $\mathrm{p}$ - significance level; $\mathrm{R}$ - right; I - left; $\mathrm{GA}-$ gonial angle; $\mathrm{RL}$ — ramus length; Rmax — maximum ramus breadth; $\mathrm{Rmin}$ — minimum ramus breadth; BiGA — bigonial width

decrease the reliability of distance measurement with PR. For this reason, PR is less reliable than $3 \mathrm{D}$ images and is not recommended for distance measurements [23].

In this study, to overcome patient positioning errors, the Frankfurt horizontal plane was adjusted parallel to the floor, and the heads of all patients were stabilised. Since it was introduced in 1998 [22], CBCT has become popular in dental diagnosis and treatment planning [5], providing 3D cross-sectional imaging, eliminating distortion and superposition situations [13]. In 2008, Berco et al. [3] investigated the accuracy and reliability of linear measurements made from CBCT scans and compared them with calliper measurements made directly on a dry human skull. The researchers reported that CBCT provides clinically accurate and reliable measurements of the craniofacial complex. Moreover, changes in skull positioning during $C B C T$ scanning do not affect the reliability or accuracy of the measurements. 
Table 5. Left mean values and significance level of all parameters in panoramic radiography (PR) and cone-beam computed tomography (CBCT) according to age

\begin{tabular}{|c|c|c|c|c|c|c|}
\hline & \multirow[t]{2}{*}{ Age groups } & \multirow[t]{2}{*}{$\mathbf{N}$} & \multicolumn{2}{|l|}{ PR } & \multicolumn{2}{|c|}{ СВCT } \\
\hline & & & Mean \pm SD & $\mathbf{P}$ & Mean \pm SD & $\mathbf{P}$ \\
\hline \multirow[t]{6}{*}{$\mathrm{L} ; \mathrm{A}$} & $10-19$ & 71 & $121.5 \pm 7.04$ & 0.439 & $119.65 \pm 6.12$ & 0.321 \\
\hline & $20-29$ & 10 & $121.71 \pm 7.31$ & & $115.2 \pm 9.79$ & \\
\hline & $30-39$ & 8 & $120.64 \pm 8.3$ & & $116.61 \pm 9.57$ & \\
\hline & $40-49$ & 14 & $117.56 \pm 6.42$ & & $117.34 \pm 6.78$ & \\
\hline & $50-59$ & 9 & $118.71 \pm 5.1$ & & $119.65 \pm 6.25$ & \\
\hline & $60-69$ & 9 & $120.91 \pm 5.61$ & & $120.04 \pm 4.92$ & \\
\hline \multirow[t]{6}{*}{$\mathrm{L} ; \mathrm{RL}$} & $10-19$ & 71 & $7.45 \pm 0.72$ & 0.179 & $5.96 \pm 0.56$ & 0.180 \\
\hline & $20-29$ & 10 & $7.69 \pm 1.14$ & & $6.3 \pm 0.96$ & \\
\hline & $30-39$ & 8 & $7.25 \pm 1.06$ & & $5.81 \pm 0.83$ & \\
\hline & $40-49$ & 14 & $8.02 \pm 1.09$ & & $6.35 \pm 0.78$ & \\
\hline & $50-59$ & 9 & $7.77 \pm 0.48$ & & $6.15 \pm 0.48$ & \\
\hline & $60-69$ & 9 & $7.68 \pm 0.78$ & & $6.16 \pm 0.5$ & \\
\hline \multirow[t]{6}{*}{ L; $\max$} & $10-19$ & 71 & $4.41 \pm 0.44$ & 0.253 & $3.86 \pm 0.38$ & $0.035^{*}$ \\
\hline & $20-29$ & 10 & $4.47 \pm 0.2$ & & $4.08 \pm 0.31$ & \\
\hline & $30-39$ & 8 & $4.31 \pm 0.42$ & & $3.92 \pm 0.44$ & \\
\hline & $40-49$ & 14 & $4.7 \pm 0.52$ & & $4.17 \pm 0.39$ & \\
\hline & $50-59$ & 9 & $4.51 \pm 0.41$ & & $4.08 \pm 0.25$ & \\
\hline & $60-69$ & 9 & $4.45 \pm 0.28$ & & $4.09 \pm 0.35$ & \\
\hline \multirow[t]{6}{*}{$\mathrm{L} ; \mathrm{Rmin}$} & $10-19$ & 71 & $3.18 \pm 0.36$ & 0.154 & $2.76 \pm 0.3$ & 0.382 \\
\hline & $20-29$ & 10 & $3.03 \pm 0.31$ & & $2.63 \pm 0.31$ & \\
\hline & $30-39$ & 8 & $3.07 \pm 0.23$ & & $2.74 \pm 0.31$ & \\
\hline & $40-49$ & 14 & $3.22 \pm 0.25$ & & $2.88 \pm 0.38$ & \\
\hline & $50-59$ & 9 & $3.04 \pm 0.36$ & & $2.67 \pm 0.32$ & \\
\hline & $60-69$ & 9 & $2.92 \pm 0.29$ & & $2.66 \pm 0.34$ & \\
\hline
\end{tabular}

${ }^{*}$ The significance level is $p<0.05 ; \mathrm{n}$ - total number of cases; mean $\pm S D$ - mean value \pm standard deviation; $p-$ significance level; $R-$ right; $\mathrm{L}-$ left; $G A-$ gonial angle; $\mathrm{RL}$ — ramus length; $\mathrm{Rmax}$ — maximum ramus breadth; $\mathrm{Rmin}$ — minimum ramus breadth; $\mathrm{BiGA}$ — bigonial width

The present study revealed that males have a larger mandibular morphology in all evaluated parameters in PR measurements, which is analogous to the results obtained by Zangouei-Booshehri et al. [36]. Males have mostly higher mandibular measurements on PR and CBCT except GA measurements. According to our PR measurements, right GA and left GA values are almost equal in males and females ( $p>0.05$ ), which is in accordance with Radhakrishnan [27], who found the mean value of the GA in females to be $122.74^{\circ}$ using PRs, and in males, $122.84^{\circ}$. The $p$-value was 0.71 , which was not statistically significant. Our study indicated that the mean value of the GA in females was $118.40^{\circ}$ on PRs, and in males, it was $119.23^{\circ}$; the $p$-value was 0.541 , which was also not statistically significant. Various PR studies $[6,12,21$,
34], both from Turkey and other populations, showed that the GA was higher in females than in males. This and some other studies [24, 30, 33], however, found no difference between GA values and gender. Different results can be attributed to the effect of the masticatory muscles such as the masseter and medial pterygoid muscles (which insert into the gonion) and forces that vary among people and affect the size of the GA $[10,15,28]$. Additionally, parafunctional habits such as bruxism and malocclusion that result in changing bite forces should be eliminated from the study [21].

Cone-beam CT examinations showed that right GA and left GA values were higher in females than in males; this difference may be attributed to the fact that the masticatory muscles are stronger in males, 
resulting in a decrease in the GA. Additionally, differences related to gender might be due to biting force and bruxism, keeping in mind that bruxism is more prevalent in women [21]. Tozoğlu and Çakur [32] evaluated 50 reformatted panoramic CBCT images to determine changes in mandibular morphology with tooth loss. In their study, the edentulous group was not included, and all patients were either dentate or partially dentate. The authors [32] showed that the GA was $123.73 \pm 12.09^{\circ}$ in the edentulous group and $119.28 \pm 7.03^{\circ}$ in the dentate group. They reported that the GA increased with tooth loss and strong masticator muscles led to a decreased GA.

Raustia and Salonen [29] performed a PR study of 30 edentulous patients, finding right-to-left differences in the GA: the right GA was significantly smaller than the left. This might be associated with masticatory muscle function on the right side. Our study showed similar results. They also found that no statistically significant difference was observed between the sexes in the sizes of the GA, and no correlation between age and size of the GA. Xie and Ainamo [34] found that the GA in edentulous older women suggested a possible systemic effect, such as metabolic bone loss, on the size of the GA. The difference in results between this study and previous studies might be due to the differences in the sample (distribution of age, gender, and dentition status).

This study showed that there was no statistically significant difference between the six age groups in all evaluated parameters on PR. For CBCT measurements, only Rmax values showed statistically significant differences on the right $(p=0.006)$ and left sides $(p=0.035)$. The lowest values for Rmax were found in the 10-19 age group and the highest in groups 40-49 and 60-69. GA measurements of both PR and CBCT did not show differences between age groups consistent with Dutra et al. [9]. However, the GA generally had higher mean values in the lowest (10-19) and highest (60-69) age groups than in the other age groups. However, no significant difference was noted between the GA and different age groups; widening of the GA in older patients has been attributed to the loss of teeth [30]. Izard [16] cited the following averages in the variability of the GA: $135^{\circ}$ to $150^{\circ}$ at birth, $130^{\circ}$ to $140^{\circ}$ when the first dentition is finished, $120^{\circ}$ to $130^{\circ}$ up to the time of eruption of the second molars; and $120^{\circ}$ to $150^{\circ}$ in old age. It can be said that GA decreases in adult age and increases again in old age. Since this was a cross-sectional study, it was difficult to arrive at a definitive conclusion about the change in GA with age, and verification is needed by longitudinal studies.

\section{CONCLUSIONS}

1. Mandibular morphology varied between age groups and genders. Measurements made in males were larger. While mandibular morphologic changes were detected among different age groups, this information needs to be verified by a longitudinal study.

2. Based on the fact that PR views showed significant differences from $C B C T$ in the morphometric measurements made in the mandible, it is recommended that forensic doctors and anthropologists consider this information in their age and gender prediction studies.

3. This study was hospital based and was limited to the Turkish population, in particular, a small Middle Anatolia population. Although the findings of this study might be useful, further researches should be conducted in other populations to determine racial differences.

\section{REFERENCES}

1. Abu-Taleb N, Beshlawy DEl. Mandibular ramus and gonial angle measurements as predictors of sex and age in an egyptian population sample: a digital panoramic study. J Forensic Res. 2015; 06(05), doi: 10.4172/21577145.1000308.

2. Al-Shamout $R$, Ammoush $M$, Alrbata $R$, et al. Age and gender differences in gonial angle, ramus height and bigonial width in dentate subjects. Pak Oral Dental J. 2012; 32(1): 81-87.

3. Berco M, Rigali PH, Miner RM, et al. Accuracy and reliability of linear cephalometric measurements from cone-beam computed tomography scans of a dry human skull. Am J Orthod Dentofacial Orthop. 2009; 136(1): 17.e1-9; discussion 17, doi: 10.1016/j.ajodo.2008.08.021, indexed in Pubmed: 19577142.

4. Bhullar MK, Uppal AS, Kochhar GK, et al. Comparison of gonial angle determination from cephalograms and orthopantomogram. Indian J Dent. 2014; 5(3): 123-126, doi: 10.4103/0975-962X.140820, indexed in Pubmed: 25565740.

5. Bremke M, Sesterhenn AM, Murthum T, et al. Digital volume tomography (DVT) as a diagnostic modality of the anterior skull base. Acta Otolaryngol. 2009; 129(10): 1106-1114, doi: 10.1080/00016480802620621, indexed in Pubmed: 19117158.

6. Chole RH, Patil RN, Balsaraf Chole S, et al. Association of mandible anatomy with age, gender, and dental status: a radiographic study. ISRN Radiol. 2013; 2013: 453763, doi: 10.5402/2013/453763, indexed in Pubmed: 24959560.

7. Coquerelle M, Bookstein FL, Braga J, et al. Sexual dimorphism of the human mandible and its association with dental development. Am J Phys Anthropol. 2011; 145(2): 192-202, doi: 10.1002/ajpa.21485, indexed in Pubmed: 21365613. 
8. Damera A, Mohanalakhsmi J, Yellarthi PK, et al. Radiographic evaluation of mandibular ramus for gender estimation: Retrospective study. J Forensic Dent Sci. 2016; 8(2): 74-78, doi: 10.4103/0975-1475.186369, indexed in Pubmed: 27555722.

9. Dutra V, Devlin H, Susin C, et al. Mandibular morphological changes in low bone mass edentulous females: evaluation of panoramic radiographs. Oral Surg Oral Med Oral Pathol Oral Radiol Endod. 2006; 102(5): 663-668, doi: 10.1016/j. tripleo.2006.02.023, indexed in Pubmed: 17052644.

10. Franklin $D$, Oxnard CE, O'Higgins $P$, et al. Sexual dimorphism in the subadult mandible: quantification using geometric morphometrics. J Forensic Sci. 2007; 52(1): 6-10, doi: 10.1111/j.1556-4029.2006.00311.x, indexed in Pubmed: 17209902.

11. Gamba Td, Alves MC, Haiter-Neto F. Mandibular sexual dimorphism analysis in CBCT scans. J Forensic Leg Med. 2016; 38: 106-110, doi: 10.1016/j.jflm.2015.11.024, indexed in Pubmed: 26773251.

12. Ghosh S, Vengal M, Pai KM, et al. Remodeling of the antegonial angle region in the human mandible: a panoramic radiographic cross-sectional study. Med Oral Patol Oral Cir Bucal. 2010; 15(5): e802-e807, doi: 10.4317/medoral.15. e802, indexed in Pubmed: 20383108.

13. Howe RB. First molar radicular bone near the maxillary sinus: a comparison of CBCT analysis and gross anatomic dissection for small bony measurement. Oral Surg Oral Med Oral Pathol Oral Radiol Endod. 2009; 108(2): 264-269, doi: 10.1016/j.tripleo.2008.12.021, indexed in Pubmed: 19201631.

14. Huumonen S, Sipilä K, Haikola B, et al. Influence of edentulousness on gonial angle, ramus and condylar height. J Oral Rehabil. 2010; 37(1): 34-38, doi: 10.1111/j.13652842.2009.02022.x, indexed in Pubmed: 19912483.

15. Ingervall $B$, Thilander B. Relation between facial morphology and activity of the masticatory muscles. J Oral Rehabil. 1974; 1(2): 131-147, indexed in Pubmed: 4525024.

16. Izard $G$. The goniomandibular angle in dentofacial orthopedia. Int J Orthod Oral Surg Radiogr. 1927; 13(7): 578-581, doi: 10.1016/s0099-6963(27)90110-0.

17. Kamburoğlu K, Kolsuz E, Kurt $H$, et al. Accuracy of $C B C T$ measurements of a human skull. J Digit Imaging. 2011; 24(5): 787-793, doi: 10.1007/s10278-010-9339-9, indexed in Pubmed: 20857166

18. Kharoshah MA, Almadani O, Ghaleb SS, et al. Sexual dimorphism of the mandible in a modern Egyptian population. J Forensic Leg Med. 2010; 17(4): 213-215, doi: 10.1016/j. jflm.2010.02.005, indexed in Pubmed: 20382358.

19. Leversha J, McKeough G, Myrteza A, et al. Age and gender correlation of gonial angle, ramus height and bigonial width in dentate subjects in a dental school in Far North Queensland. J Clin Exp Dent. 2016; 8(1): e49-e54, doi: 10.4317/jced.52683, indexed in Pubmed: 26855706.

20. Ludlow JB, Laster WS, See M, et al. Accuracy of measurements of mandibular anatomy in cone beam computed tomography images. Oral Surg Oral Med Oral Pathol Oral Radiol Endod. 2007; 103(4): 534-542, doi: 10.1016/j. tripleo.2006.04.008, indexed in Pubmed: 17395068.

21. Mağat G, Şener SÖ. The morphological changes in the mandible bone: the effects of age, gender and dental status. Meandros Med Dent J. 2018; 19(2): 111-120, doi: $10.4274 /$ meandros.02886

22. Mozzo P, Procacci C, Tacconi A, et al. A new volumetric CT machine for dental imaging based on the cone-beam technique: preliminary results. Eur Radiol. 1998; 8(9): 1558-1564, indexed in Pubmed: 9866761.

23. Nishikawa K, Suehiro A, Sekine $H$, et al. Is linear distance measured by panoramic radiography reliable? Oral Radiol. 2010; 26(1): 16-19, doi: 10.1007/s11282-010-0038-5.

24. Ohm E, Silness J. Size of the mandibular jaw angle related to age, tooth retention and gender. J Oral Rehabil. 1999; 26(11): 883-891, indexed in Pubmed: 10583739.

25. Panneerselvam E, Prasad PJ, Balasubramaniam S, et al. The influence of the mandibular gonial angle on the incidence of mandibular angle fracture: a radiomorphometric study. J Oral Maxillofac Surg. 2017; 75(1): 153-159, doi: 10.1016/j. joms.2016.08.016, indexed in Pubmed: 27643630.

26. Poongodi V, Kanmani R, Anandi MS, et al. Prediction of age and gender using digital radiographic method: A retrospective study. J Pharm Bioallied Sci. 2015; 7(Suppl 2): S504-S508, doi: 10.4103/0975-7406.163518, indexed in Pubmed: 26538907.

27. Radhakrishnan PD, Sapna Varma NK, Ajith VV. Dilemma of gonial angle measurement: Panoramic radiograph or lateral cephalogram. Imaging Sci Dent. 2017; 47(2): 93-97, doi: 10.5624/isd.2017.47.2.93, indexed in Pubmed: 28680845 .

28. Rando C, Hillson S, Antoine D. Changes in mandibular dimensions during the mediaeval to post-mediaeval transition in London: a possible response to decreased masticatory load. Arch Oral Biol. 2014; 59(1): 73-81, doi: 10.1016/j.archoralbio.2013.10.001, indexed in Pubmed: 24169153.

29. Raustia AM, Salonen MA. Gonial angles and condylar and ramus height of the mandible in complete denture wearers--a panoramic radiograph study. J Oral Rehabil. 1997; 24(7): 512-516, indexed in Pubmed: 9250838.

30. Rupa KR, Chatra L, Shenai $P$, et al. Gonial angle and ramus height as sex determinants: A radiographic pilot study. J Craniomax Dis. 2015; 4(2): 111, doi: 10.4103/2278-9588.163247.

31. Srineeraja P. Determination of Angle of Mandible from Mandibular Bones and Orthopantomograph. J Pharm Sci Res. 2015; 7(8): 589-581.

32. Tozoğlu U, Cakur B. Evaluation of the morphological changes in the mandible for dentate and totally edentate elderly population using cone-beam computed tomography. Surg Radiol Anat. 2014; 36(7): 643-649, doi: 10.1007/ s00276-013-1241-y, indexed in Pubmed: 24292424.

33. Upadhyay RB, Upadhyay J, Agrawal P, et al. Analysis of gonial angle in relation to age, gender, and dentition status by radiological and anthropometric methods. J Forensic Dent Sci. 2012; 4(1): 29-33, doi: 10.4103/09751475.99160, indexed in Pubmed: 23087579.

34. Xie QF, Ainamo A. Correlation of gonial angle size with cortical thickness, height of the mandibular residual body, and duration of edentulism. J Prosthet Dent. 2004; 91(5): 477-482, doi: 10.1016/S0022391304001118, indexed in Pubmed: 15153856.

35. Yanikoğlu N, Yilmaz B. Radiological evaluation of changes in the gonial angle after teeth extraction and wearing of dentures: a 3-year longitudinal study. Oral Surg Oral Med Oral Pathol Oral Radiol Endod. 2008; 105(6): e55-e60, doi: 10.1016/j.tripleo.2008.02.014, indexed in Pubmed: 18417386.

36. Zangouei-Booshehri M, Aghili HA, Abasi M, et al. Agreement between panoramic and lateral cephalometric radiographs for measuring the gonial angle. Iran J Radiol. 2012; 9(4): 178-182, doi: 10.5812/iranjradiol.8444, indexed in Pubmed: 23407613. 